\title{
Circumpolar plant nutrient covariation in the Southern Ocean: patterns and processes
}

\author{
Daniel Kamykowski, Sara-Joan Zentara \\ Department of Marine, Earth and Atmospheric Sciences, North Carolina State University, Raleigh, North Carolina 27695-8208, \\ USA
}

\begin{abstract}
Phosphate from the NODC data set is substituted for nitrate in a regression relationship with silicic acid based on the NODC data set to broaden a previous, spatially-limited analysis of nitrogen and silicic acid fluxes in the Southern Ocean $\left(30^{\circ} \mathrm{S}\right.$ to Antarctica). The log slope of the phosphate-silicic acid relation, an index of plant nutrient utlization rates, provides a complete circumpolar view and supports more detailed speculation on the processes that contribute to the spatial and temporal patterns. A log $\mathrm{PO}_{4}$-Si slope criterion of -1.6 parallels a previous $\log \mathrm{NO}_{3}$-Si slope criterion of -0.5 where low log $\mathrm{NO}_{3}$-Si slopes more negative than the criterion were attributed to higher ammonium flux. Three regions are distinguished by these criteria including an area of mixed low and high log slopes south of the Antarctic Divergence, an area of predominantly low log slopes between the Antarctic Divergence and the Antarctic Polar Front, and an area of predominantly high log slopes north of the Antarctic Polar Front. The middle low log slope region is most restricted in austral winter and spring and most broadly distributed in austral summer and fall. Based on recent information from the Southern Ocean, the processes that are likely contributors to the occurrence of high or low log slopes are extended to include not only ammonium fluxes, but also particulate Si:N molar ratios (and therefore implied Si: $\mathrm{N}$ uptake ratios) ranging up to $4: 1$ and possible iron limitation. The invoked processes apply both to $\mathrm{NO}_{3}-\mathrm{Si}$ and $\mathrm{PO}_{4}$-Si relationships except that excreted phosphorus atoms are not preferentially selected from the total phosphorus pool as occurs for ammonium from the total nitrogen pool. The continuous presence of low log slopes in various regions of the Southern Ocean throughout the year suggests a strong potential for ammonium preference in response to a dominating ammonium supply or to iron limitation and/or for relatively high Si: $N$ uptake ratios to occur throughout the annual cycle. The nutrient relationships from the Southern Ocean provide a record of the integrated processes that influence net plant nutrient utilization rates over the growth season. However, since a given log slope can represent a variety of process combinations, more information will be required to accurately interpret the exact sequence of processes that contribute to the nutrient signature in the Southern Ocean at a given time and place.
\end{abstract}

\section{INTRODUCTION}

Three previous surveys that examined how nitrate $\left(\mathrm{NO}_{3}\right)$ and silicic acid (Si) concentrations co-vary in the Pacific Ocean (Zentara \& Kamykowski 1977, 1981) and in the world ocean (Kamykowski \& Zentara 1985, hereafter $\mathrm{KZ}$ 1985) emphasize the unique character of the Southern Ocean. This uniqueness is related to the large range of dissolved $\mathrm{Si} \mathrm{NO}_{3}$ ratios (all units are mole-based) that occur between the Southern Subtropical Convergence and Antarctica. The extremes of this range can apparently extend from ca $70 \mu \mathrm{M}$ silicic acid at projected nitrate depletion (the intercept based on the regression trend of the available points) to ca $30 \mu \mathrm{M}$ nitrate at projected silicic acid depletion (Zentara \& Kamykowski 1981). These previous surveys provide limited circumpolar coverage because nitrate determinations are rare between longitudes $0^{\circ}$ and $120^{\circ} \mathrm{E}$ in the Atlantic and Indian sectors of the Southern Ocean (Gordon et al. 1982). This historical data gap can be attributed to the increased analytical difficulty associated with nitrate measurements and to the remoteness of the region. The present paper seeks to extend the circumpolar view by substituting phosphate for nitrate in an investigation of how phosphate $\left(\mathrm{PO}_{4}\right)$ and silicic acid co-vary in the Southern Ocean as recorded in the NODC (National Oceanographic Data Center) data set. This substitution is based on the observation that the inorganic $\mathrm{NO}_{3}: \mathrm{PO}_{4}$ ratio in deep ocean water and the organic N:P ratio in the upper ocean are ca 16:1 (Redfield et al. 1963). Since the exact value (Takahashi et al 1985, Smith et al. 1986) and the constancy (Broecker \& 
Peng 1982, Harris 1986) of these ratios are under continuing scrutiny and since a multiple source data set is likely to exhibit increased analytical error, the present effort will begin with an investigation of how paired concentrations of nitrate and phosphate covary in the NODC data set (data from many sources) as compared to the GEOSECS data set (a coordinated global effort). Broecker \& Peng (1982) discussed the constancy of the $\mathrm{NO}_{3}: \mathrm{PO}_{4}$ ratio in GEOSECS and demonstrated its utility by computing nitrate deficits in denitrification regions based on the subtraction of the measured nitrate concentration from 15 times the simultaneously determined phosphate concentration.

The previously identified plant nutrient patterns in the Southern Ocean (LeJehan \& Treguer 1983, 1985 KZ 1985) have been discussed in terms of phytoplankton species composition, the temperature-dependent kinetics of biogenic silica production and dissolution (Nelson \& Gordon 1982) and a regionally variable flux of ammonium (Olson 1980, Gilbert et al. 1982), a preferred phytoplankton nitrogen source (McCarthy 1981). Subsequent information provides a broader perspective from which to interpret the Southern Ocean plant nutrient patterns. First, seasonal ice dynamics south of the Polar Front significantly influence water column stability to yield receding ice-edge diatom blooms that can support particulate $\mathrm{Si} N \mathrm{~N}$ ratios and, by inference, $\mathrm{Si}: \mathrm{N}$ uptake ratios as high as $4: 1$ if a C:N ratio of 6.6 is assumed (Nelson \& Smith 1986 , Smith 1987). Second, Collos \& Slawyk (1986) propose that nitrate and not ammonium is the major nitrogen source south of the Polar Front based on dual label measurements using ${ }^{13} \mathrm{C}$ and ${ }^{15} \mathrm{~N}-\mathrm{NO}_{3}$. In contrast, Hewes et al. (1985) emphasize the role of alternate microbial food webs based on rapid recycling and an apparent differential preference for ammonium among nannophytoplankton (Sakshaug \& Holm-Hansen 1984). Third, Martin \& Fitzwater (1988) and Martin \& Gordon (1988) suggest that iron limits phytoplankton growth in the Southern Ocean. The present paper also seeks to apply this evolving view of the Southern Ocean phytoplankton dynamics to a more comprehensive understanding of the circumpolar plant nutrient patterns provided by the NODC data set.

\section{METHODS}

Data from oceanographic stations at which nitrate and silicic acid concentrations or phosphate and silicic acid concentrations were determined in parallel were obtained from the GEOSECS tapes (provided by Scripps Institution of Oceanography) and the NODC tapes used by Kamykowski \& Zentara (1986). All nutrients in this paper are reported in mole-based units characteristic of the original data sets. This NODC data set in Station Data II format was obtained ca 2 yr after the NODC data set in Station Data I format reported in KZ (1985). The general criteria used to yield representative linear regressions generally followed those applied in $\mathrm{KZ}$ (1985) except for the following: (1) pre1962 data were included because the already large variance of the post-1962 data was not increased; (2) the low phosphate cutoff to eliminate points along the axis was set at $0.1 \mu \mathrm{M}$; and, (3) the upper cutoffs for the slopes and standard deviations were eliminated. The latter 2 criteria were also applied to the GEOSECS data base. Briefly, the remaining criteria from $K Z$ (1985) were: (1) salinity $\geq 30 \%$, (2) nitrate $\geq 2 \mu \mathrm{M}$, (3) silicic acid $\geq 2 \mu \mathrm{M}_{1}$ (4) if latitude $\geq 60^{\circ} \mathrm{S}$, the lower boundary of upper water column was set at $200 \mathrm{~m}$; if latitude $<$ $60^{\circ} \mathrm{S}$ but $\geq 30^{\circ} \mathrm{S}$, the lower boundary of the upper water column was set at $500 \mathrm{~m}$; (5) the slope of the regression lines $\geq 0.00001$; and (6) the standard deviation $\geq 0.00001$. In addition, values of temperature, salinity, nitrate, phosphate or silicic acid in the NODC data set beyond the normal range of oceanographic values (Sverdrup et al. 1942) were divided by 10 in an attempt to minimize errors in decimal point position.

The Statistical Analysis System (SAS Institute Inc. 1985) was used for the statistical computations and the $x-y$ plots. DISSPLA (ISSCO 1981) was used to generate the Southern Ocean maps. Some of the processes that can influence the character of the plant nutrient relationships during a growth season were examined using a FORTRAN-based computer model. The model required definition of starting concentrations at the beginning of the growth season $\left(\mathrm{NO}_{3}=31 \mu \mathrm{M}, \mathrm{Si}=\right.$ $78 \mu \mathrm{M})$, relative uptake rates for the different plant nutrients $\left(\mathrm{NO}_{3} / \mathrm{Si}=1: 1\right.$ to $\left.4: 1\right)$, a supply rate of the preferred ammonium nitrogen source (0 to $100 \%$ ) and a dissolution rate $(30 \%)$ for biogenic silica. Nitrate regeneration was assumed negligible in the euphotic zone (Olson 1981). The model provides a summary of the relative plant nutrient concentrations in the water column that result under a specific set of conditions.

\section{RESULTS}

Phosphate must reliably co-vary with nitrate in the NODC data base to coherently extend the $\mathrm{NO}_{3}$-Si patterns previously described in the Southern Ocean (here defined as the region between $30^{\circ} \mathrm{S}$ to Antarctica). The NODC $\mathrm{PO}_{4}-\mathrm{NO}_{3}$ relationships were compared to the standard provided by similar relationships from the higher quality GEOSECS data base (Broecker \& Peng 1982 ) in 2 cases. The first comparison used a subset of the NODC stations that fell along the track of the GEOSECS stations in the world ocean. The NODC and 
the corresponding GEOSECS subsets were obtained by merging GEOSECS and NODC data sets based on integer degrees of latitude and longitude. The GEOSECS stations that remained after the merge represent the world ocean and mark one corner of a $1^{\circ}$ latitude by $1^{\circ}$ longitude square within which the NODC stations can occur. The $\mathrm{PO}_{4}-\mathrm{NO}_{3}$ relationship from the subset of NODC stations is compared with the subset of the higher quality GEOSECS data base in Fig. 1. Although GEOSECS contains more points ( $n=2530$ ), the confidence limits of the NODC data ( $n=2038$ ) are about twice as wide. The NODC data also have outliers far outside the envelope provided by the $95 \%$ confidence limits. This comparison, emphasizing open ocean locations, demonstrates that the central tendencies of the 2 data sets are very similar (GEOSECS: $\mathrm{PO}_{4}$ $=0.097+0.066 \mathrm{NO}_{3}$ NODC: $\mathrm{PO}_{4}=0.278+0.062 \mathrm{NO}_{3}$ ) but that the NODC data exhibit a higher residual variance (GEOSECS: $\mathrm{r}^{2}=0.97$; NODC: $\mathrm{r}^{2}=0.83$ ).
Since the focus of the present analysis is the Southern Ocean, the second comparison of the 2 data sets used all of the data from south of $30^{\circ} \mathrm{S}$ for both GEOSECS and NODC. For NODC data, this subset included a large number of coastal stations (salinity approaching the $30 \%$ minimum) that could influence the $\mathrm{NO}_{3} / \mathrm{PO}_{4}$ ratio. Fig. 2 demonstrates the excellent relationship in the GEOSECS data (left) for this restricted set of oceanic observations ( $n=629$ ) and a more extensive outlier problem in the NODC data (right) than occurred in Fig. 1. Since the NODC plot represents 38282 points, ca 1900 points lie outside the $95 \%$ confidence limits. Again the central tendencies are very similar (GEOSECS: $\mathrm{PO}_{4}=0.147+0.063 \mathrm{NO}_{3}$; NODC: $\mathrm{PO}_{4}=0.312+0.059 \mathrm{NO}_{3}$ ) but the band within the $95 \%$ confidence limits of the NODC data is 6 times wider than the GEOSECS data.

These 2 comparisons demonstrate that the $\mathrm{PO}_{4}-\mathrm{NO}_{3}$ relationship in the NODC data set generally overlays
Fig. 1 Comparison of phosphate-nitrate plots from (A) GEOSECS and (B) NODC representing the world ocean. The GEOSECS data are described by $\mathrm{PO}_{4}=$ $0.097+0.066 \mathrm{NO}_{3}, \mathrm{n}=2530, \mathrm{r}^{2}=0.97$ The NODC data are described by $\mathrm{PO}_{4}=$ $0.278+0.062 \mathrm{NO}_{3}, \mathrm{n}=2038, \mathrm{r}^{2}=0.83$. Dashed lines represent $95 \%$ confidence limits for an individual prediction

Fig. 2. Comparison of phosphate-nitrate plots from (A) GEOSECS and (B) NODC for water depths $<200 \mathrm{~m}$ south of $60^{\circ} \mathrm{S}$ and $<500 \mathrm{~m}$ between 60 and $30^{\circ} \mathrm{S}$ for salinities $\geq 30 \%$. The GEOSECS data are described by $\mathrm{PO}_{4}=0.147+0.063$ $\mathrm{NO}_{3}, \mathrm{n}=629, \mathrm{r}^{2}=0.99$. The NODC data are described by $\mathrm{PO}_{4}=0.312+0.059$ $\mathrm{NO}_{3}, \mathrm{n}=38282, \mathrm{r}^{2}=0.73$. Dashed lines represent $95 \%$ confidence limits for an individual prediction
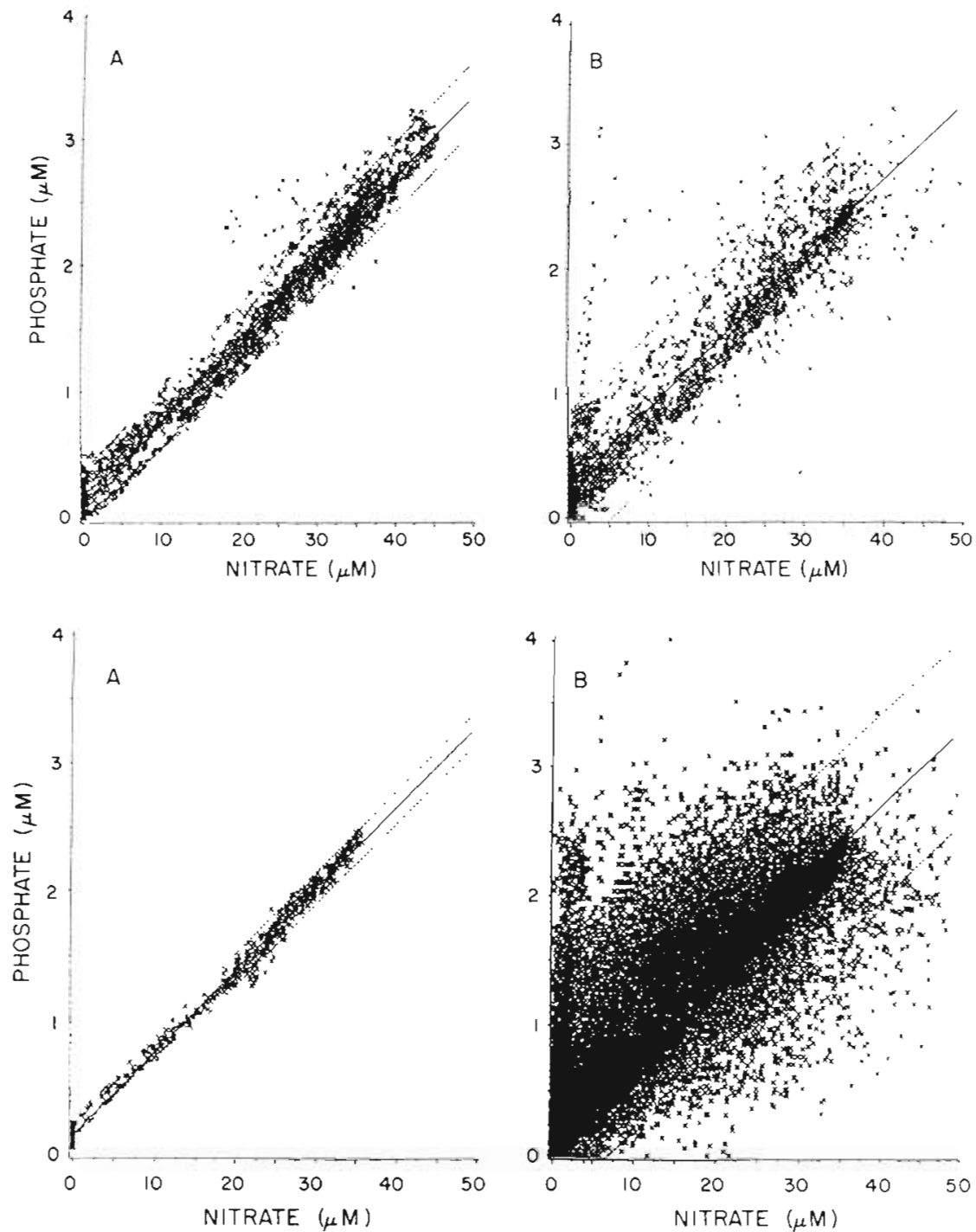
the corresponding relationship as recorded in the GEOSECS data set. The spatial patterns from the NODC $\mathrm{PO}_{4}-\mathrm{Si}$ relationships will, therefore, approximate the actual pattern as defined by GEOSECS and will complement the Southern Ocedan pattern as previously provided by the NODC $\mathrm{NO}_{3}$-Si relationships. The higher variability in the $\mathrm{NODC} \mathrm{PO}_{4}-\mathrm{NO}_{3}$ relationships suggests that the spatial pattern based on the NODC $\mathrm{PO}_{4}-\mathrm{Si}$ relationships will be considerably less precise than those based on GEOSECS and can occasionally deviate from the NODC $\mathrm{NO}_{3}-\mathrm{Si}$ relationships where both occur.

$\mathrm{KZ}$ (1985) argued that the slope of the $\mathrm{NO}_{3}$-Si regression relationship was sensitive to and contained information on the underlying Southern Ocean nutrient fluxes in time and space. The chosen approximate boundary between actual or extrapolated (no zero nutrient concentrations at a station) intercepts on the silicic acid axis or the nitrate axis was a log slope equal to -0.5. (Log slopes were used to expand the view of slopes between 0 and 1.) According to the previous interpretation, $\log$ slopes greater than -0.5 represented nitrate as the dominant nitrogen source and log slopes less than -0.5 represented ammonium as the dominant nitrogen source. Fig. 3 displays the relationship between the log slopes derived from $\mathrm{PO}_{4}-\mathrm{Si}$ regressions compared to those derived from $\mathrm{NO}_{3}-\mathrm{Si}$ regressions for $\mathrm{NODC}$ stations south of $30^{\circ} \mathrm{S}$ at which all 3 plant nutrients were measured simultaneously.

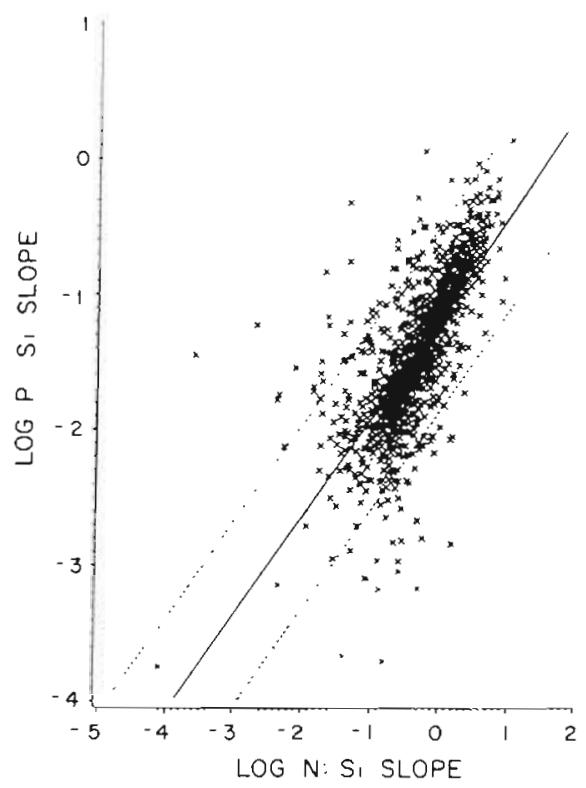

Fig. 3. Plot demonstrating the relationship between log slopes of the nitrate-silicic acid regressions (LNSSLP) and log slope of the phosphate-silicic acid regressions (LPSSLP) from the same NODC stations south of $30^{\circ} \mathrm{S}$. The data are described by LPSSLP $=1.217487+0.713426$ LNSSIP, $\mathrm{n}=1480, \mathrm{r}^{2}=0.54$ Dashed lines represent $95 \%$ confidence limits for an individual prediction
This plot suggests that the regression relationship reduces the effect of outliers and provides a log slope of -1.6 for the $\mathrm{PO}_{4}$-Si relationship to correspond to the previously used log slope of -0.5 for the $\mathrm{NO}_{3}-\mathrm{Si}$ relationship. For immediate purposes, the general arguments concerning the factors that influence the relationship between the slopes and intercepts for the $\mathrm{NO}_{3}$-Si data based on estimated initial nutrient concentrations, ammonium preference and the prevailing view of nutrient uptake kinetics (KZ 1985) are also generally applicable to the $\mathrm{PO}_{4}-\mathrm{Si}$ data. Phosphorus from regenerated sources is assumed to offset the nonselective phosphate uptake accompanying ammonium uptake. Modifications to these concepts will be discussed later.

Fig. 4, based on the re-computed $\mathrm{NO}_{3}$-Si regressions, displays the station locations that are characterized by $\log$ slopes less than (Fig. 4A) or greater than (Fig. 4B) -0.5 . This figure, based on the more recent data set in Station Data II format and the previously stated changes in criteria, exhibits a pattern that is nearly identical to that presented in KZ (1985). Fig. 5, based on the $\mathrm{PO}_{4}$-Si regressions, displays the station locations that are characterized by log slopes less than (Fig. 5A) or greater than (Fig. 5B) -1.6. In contrast to the data in Fig. 4, these stations occur throughout the Southern Ocean including the eastern Atlantic and Indian sectors.

A more detailed comparison of Fig. 4 and 5 shows that the 2 left plots and the 2 right plots are very similar to each other over the regions within which they both have data. Fig. 5A continues the pattern from the corresponding regions with Fig. $4 \mathrm{~A}$ into the regions where only the $\mathrm{PO}_{4}$-Si data are represented. The low log slope stations occur most commonly in a zone bounded by Antarctica and the Antarctic Polar Front except off the coast of Argentina. Ikeda et al. (1989) discuss the variability of the frontal structure between Southern Brazil and the Antarctic Pennisula. Fig. 5B also continues the pattern from the corresponding regions with Fig. $4 \mathrm{~B}$ into regions where only $\mathrm{PO}_{4}-\mathrm{Si}$ data are represented. Fig. $4 \mathrm{~B}$ and $5 \mathrm{~B}$ are less clearly bounded than Fig. $4 \mathrm{~A}$ and $5 \mathrm{~A}$. The high $\log$ slope stations are scattered throughout the Southern Ocean with an increased incidence near Antarctica and north of the Polar Front (Tchernia 1980). The concentration of stations with high log slopes previously identified in the Ross Sea and Weddell Sea (KZ 1985) occur around Antarctica in the $\mathrm{PO}_{4}$-Si analysis.

Figs. 4 and 5 suggest that at least 3 circumpolar zones exist in the Southern Ocean. Fig. 6 which groups the stations for $\mathrm{NO}_{3}-\mathrm{Si}$ (Fig. 6A) and $\mathrm{PO}_{4}-\mathrm{Si}$ (Fig. 6B) into $1^{\circ}$ latitudinal bands provides a clearer view of the pattern. This approach, of course, assumes perfect radial symmetry around the South Pole that neither the 

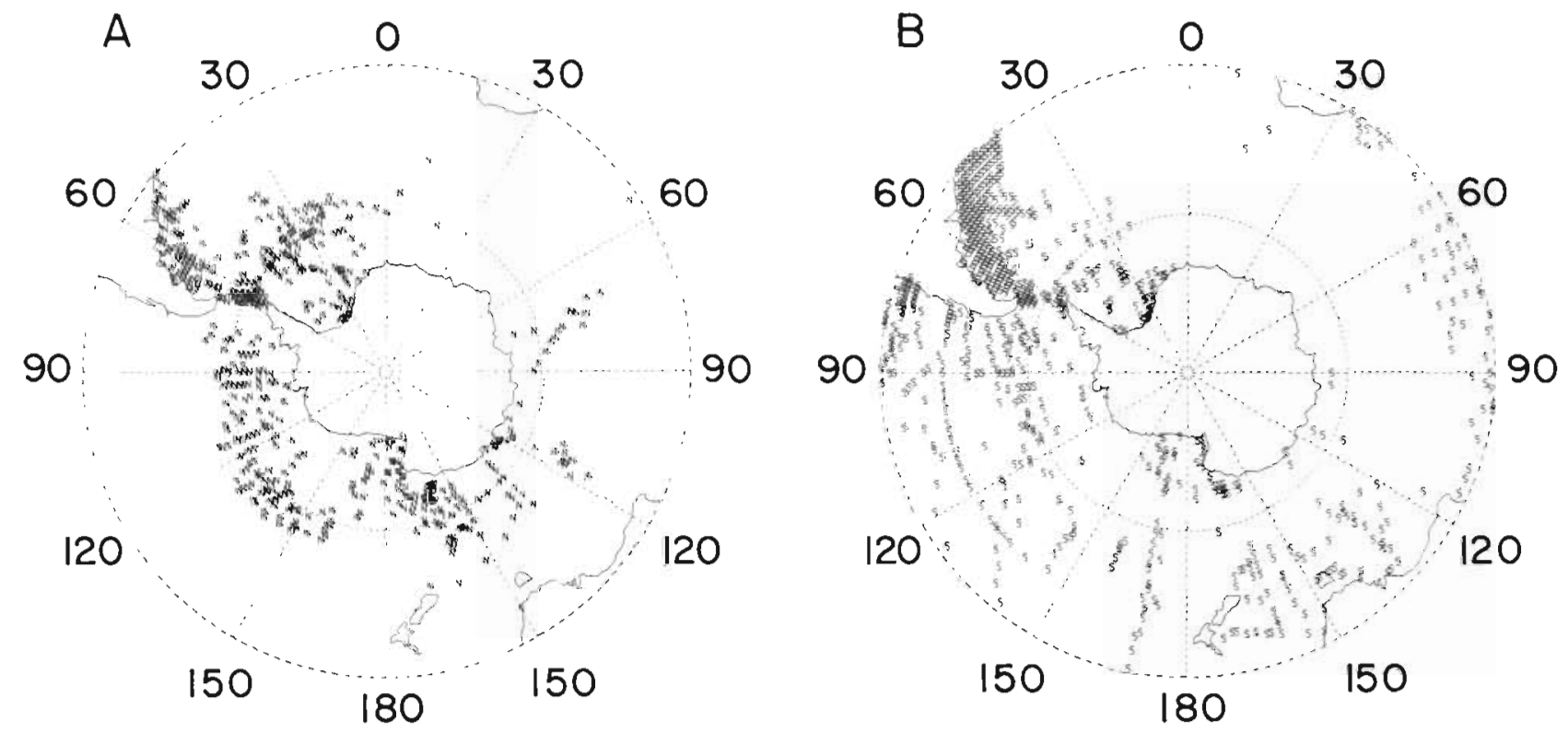

Fig. 4. Distribution of NODC stations south of $30^{\circ} \mathrm{S}(\mathrm{n}=1763)$ for $\log$ slopes from the nitrate-silicic acid regressions either (A) less than -0.5 where the symbol ' $N$ ' represents a tendency toward intercepts on the positive nitrate axis or (B) greater than -0.5 where the symbol ' $\mathrm{S}$ ' represents a tendency toward intercepts on the positive silicic acid axis
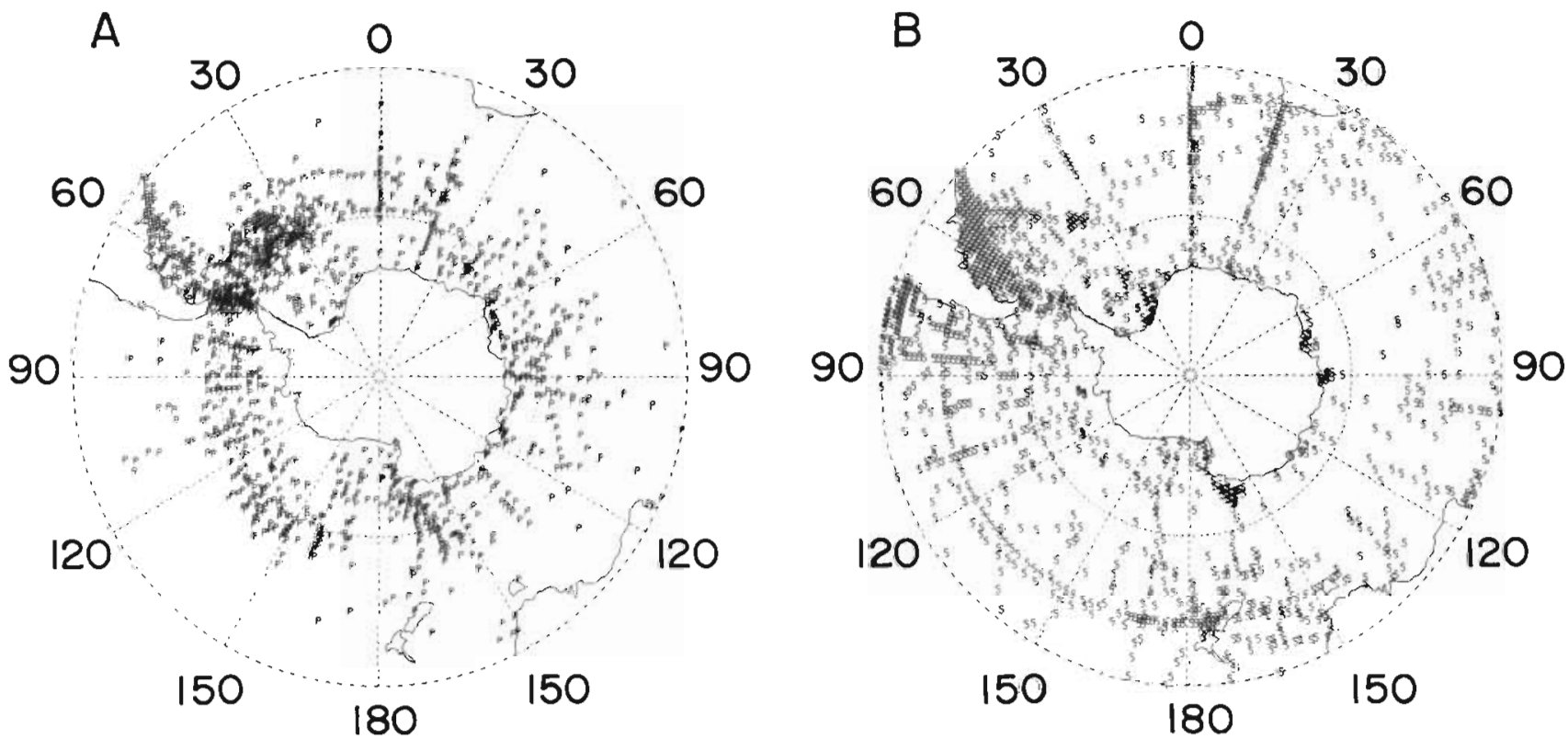

Fig. 5. Distribution of NODC stations south of $30^{\circ} \mathrm{S}(\mathrm{n}=3580)$ for log slopes from the phosphate-silicic acvid regressions either (A) less than -1.6 where the symbol ' $\mathrm{P}$ ' represents a tendency toward intercepts on the positive phosphate axis or (B) greater than -1.6 where the symbol ' $S$ ' represents a tendency toward intercepts on the positive silicic acid axis

land mass nor the water masses actually follow. Deviations from radial symmetry will tend to weaken the expression of more complicated circumpolar tendencies that actually exist. Fig. 6C, D display the percent of low log slopes for $\mathrm{NO}_{3}$-Si and $\mathrm{PO}_{4}$-Si, respectively. The most southern zone, extending from the coast of Antarctica to about $66^{\circ} \mathrm{S}$, exhibits a nearly equal occurrence of low or high log slopes (Fig. 6C) or a slight tendency toward high log slopes (Fig. 6D). This zone appears bounded by Antarctica and the Antarctic Divergence (63 to $65^{\circ} \mathrm{S}$; Tchernia 1980). From 66 to $52^{\circ} \mathrm{S}$, low $\log$ slopes are more likely than high $\log$ slopes (Fig. 6C, D). The boundary at $52^{\circ} \mathrm{S}$ generally coincides with the location of the Antarctic Polar Front (46 to $62^{\circ} \mathrm{S}$; Tchernia 1980). This region dominated by low log slopes is characterized by average surface temperatures between -1.5 and $+5^{\circ} \mathrm{C}$ and with average surface salinities between 33.6 and $34.1 \%$. The 

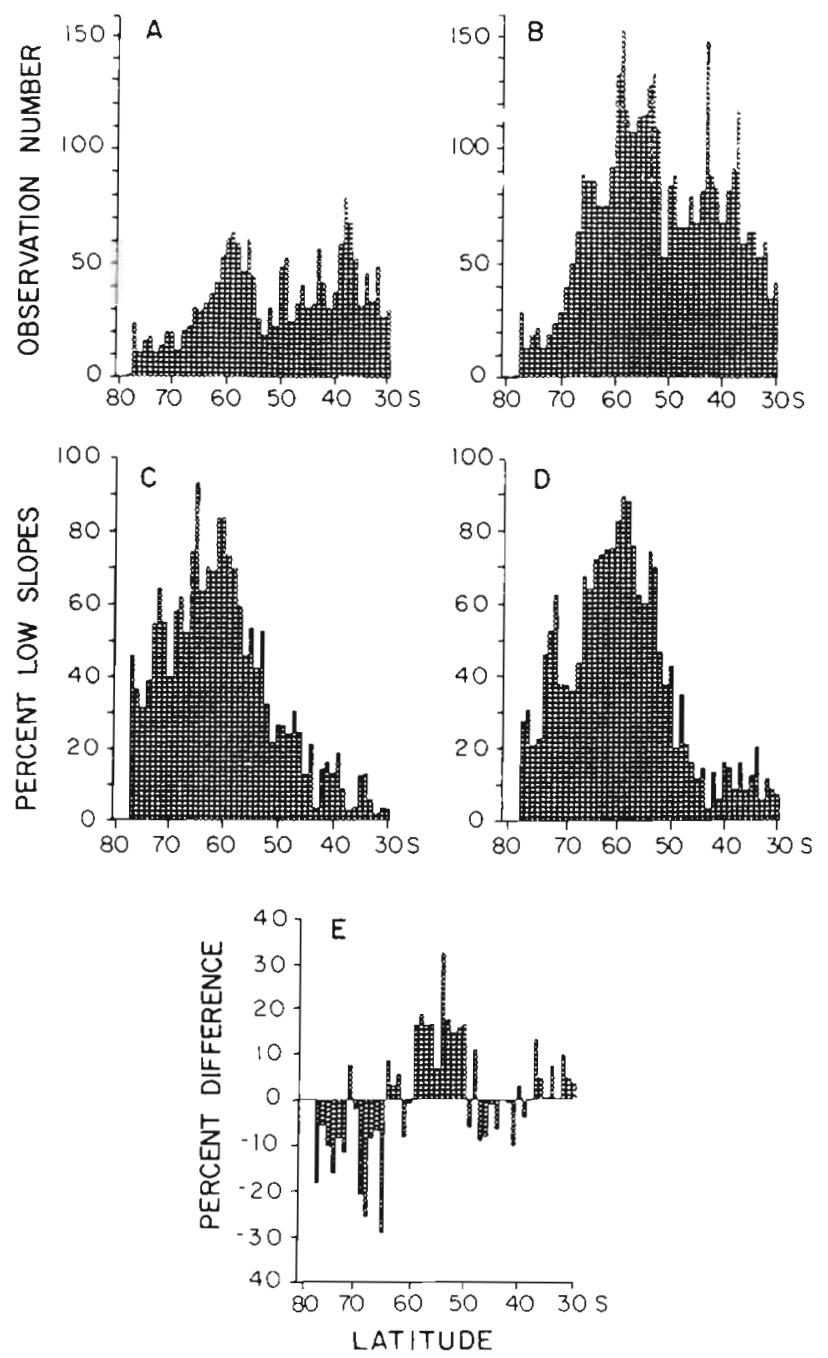

Fig. 6. (A, B) Number of stations; (C, D) percent log slopes less than $-0.5(C)$ or $-1.6(D)$; and $(E)$ the difference (D-C) between these percents for nitrate-silicic acid (A, C) and phosphate-silicic acid $(B, D)$ in $1^{\circ}$ latitudinal bands in the Southem Ocean

greatest frequency of low log slopes occurs around $60^{\circ} \mathrm{S}$ in average surface conditions of $1.8^{\circ} \mathrm{C}$ and $33.9 \%$. This latitude is at or within a few degrees of the most northern extension of the winter ice pack (Tchernia 1980). North of $52^{\circ} \mathrm{S}$, high log slopes are more likely than low log slopes (Fig. 6C, D). The southern part of this zone is characterized by silicic acid depletion with nitrate and phosphate in excess in the near surface waters; the northern part of this zone is characterized by depletion of all 3 plant nutrients in surface waters ( $\mathrm{KZ}$ 1985). The regression relationships thus initiate at the base of the mixed layer. Fig. $6 \mathrm{E}$ demonstrates that the calculations based on $\mathrm{NO}_{3}-\mathrm{Si}$ or $\mathrm{PO}_{4}-\mathrm{Si}$ generally agree within $\pm 15 \%$ although a few latitudinal bands deviate by as much as $\pm 30 \%$.

Tables $1\left(\mathrm{NO}_{3}-\mathrm{Si}\right)$ and $2\left(\mathrm{PO}_{4}-\mathrm{Si}\right)$ list the log of the monthly mean slopes that occur in $5^{\circ}$ latitudinal bands around Antarctica from 70 to $30^{\circ} \mathrm{S}$. The influence of the annual ice edge migration is discernible in the boundary of available data in the most southern latitudes. The $\log$ slopes at or below -0.5 and -1.6 , respectively, occur throughout the year between 64 and $55^{\circ} \mathrm{S}$ and tend to extend south to $69^{\circ} \mathrm{S}$ from austral spring through austral autumn and north to $50^{\circ} \mathrm{S}$ from late austral summer through austral winter. The temporal persistence of low log slopes suggests that the processes required to maintain this condition occur in the Southern Ocean throughout the year. The low log slopes tend toward more negative values in austral autumn-winter than in austral spring-summer possibly due to changing ammonium influence as the growth season progresses (KZ 1985).

\section{DISCUSSION}

Nitrogen is excreted in reduced forms (ammonium or organic molecules) that are often preferred phytoplankton nitrogen sources compared to the prevalent nitrate pool in the water column (McCarthy 1981). Phosphorus, on the other hand, is excreted either as organic phosphorus, a non-preferred phosphorus source, or as phosphate, the dominant molecular form of the phosphorus pool in the water column (Omori \& Ikeda 1984). In contrast to phosphorus, a small percentage of the available nitrogen atoms apparently cycle through the food web several times when regeneration is a dominant process. The frequent recycling of a relatively small subpopulation of nitrogen atoms may influence the isotopic composition of the ammonium and particulate nitrogen throughout the growth season due to fractionation (Wada 1980, Checkley \& Entzeroth 1985, Altabet 1988). This isotope drift may eventually provide an additional tool that can be used with plant nutrient ratios to distinguish the various processes contributing to the plant nutrient patterns in the Southern Ocean.

Selected aspects of nutrient uptake relationships and temperature-dependent silicâ dissolution were previously invoked to explain the observed plant nutrient patterns in the Southern Ocean (LeJehan \& Treguer 1983, 1985, KZ 1985). Recent studies suggest that the combination of factors chosen by $\mathrm{KZ}$ (1985) to explain their derived $\mathrm{NO}_{3}$-Si relationships may represent only one intermediate example drawn from a more complex set of processes. Fig. 7 is derived from a FORTRANbased computer model that is capable of examining the interaction between various levels of ammonium preference and $\mathrm{NO}_{3}$-Si uptake ratios. As a starting point, the model was applied with the conditions used in $\mathrm{KZ}$ (1985) (starting $\mathrm{NO}_{3}=31 \mu \mathrm{M}$, starting $\mathrm{Si}=$ 
Table 1. Log of monthly mean slopes from the nitrate-silicic acid relationships for $5^{\circ}$ bands of latitude around Antarctica. The Listed latitude represents that latitude and $4^{\circ}$ south (i.e. $-65=65$ to $69^{\circ} \mathrm{S}$ ) except for -70 which extends south to Antarctica. Months are numbered 1 (Jan) to 12 (Dec) but are ordered according to Southern Hemisphere spring, summer, autumn and winter Log slopes $\leq-0.5$ are included within the boxed region. Underlined numbers are based on 5 or less values

\begin{tabular}{|c|c|c|c|c|c|c|c|c|c|}
\hline \multirow[t]{2}{*}{ Month } & \multicolumn{9}{|c|}{ Latitude } \\
\hline & -70 & -65 & -60 & -55 & -50 & -45 & -40 & -35 & -30 \\
\hline 10 & - & -0.5 & -0.6 & -0.4 & 0.2 & 0.0 & 0.2 & 0.3 & 0.5 \\
\hline 11 & - & -0.7 & -0.1 & -0.3 & 0.1 & 0.2 & 0.0 & 0.4 & 0.4 \\
\hline 12 & - & -0.7 & -0.6 & -0.5 & -0.2 & 0.1 & 0.3 & 0.4 & $\underline{0.2}$ \\
\hline 1 & -0.4 & -0.5 & -0.6 & -0.5 & 0.2 & 0.3 & 0.3 & 0.3 & 0.2 \\
\hline 2 & -0.4 & -0.5 & -0.5 & -0.5 & -0.1 & 0.0 & 0.3 & 0.3 & 0.4 \\
\hline 3 & -0.3 & -0.4 & -0.5 & -0.4 & -0.6 & 0.3 & 0.3 & 0.4 & 0.2 \\
\hline 4 & - & -0.7 & -0.7 & -0.3 & 0.1 & 0.4 & 0.1 & 0.4 & 0.2 \\
\hline 5 & - & - & -0.7 & -0.6 & -0.7 & -0.2 & 0.0 & 0.1 & 0.2 \\
\hline 6 & - & -0.7 & -0.6 & -0.5 & -0.3 & -0.5 & -0.3 & 0.0 & 0.2 \\
\hline 7 & - & - & -0.7 & -0.6 & -0.4 & -0.5 & 0.1 & 0.1 & 0.3 \\
\hline 8 & - & - & -0.9 & -0.6 & -0.4 & 0.0 & 0.1 & 0.1 & 0.3 \\
\hline 9 & - & - & - & -0.6 & -0.4 & 0.1 & 0.1 & 0.2 & 0.4 \\
\hline
\end{tabular}

Table 2. Log of monthly mean slopes from the phosphate-silicic acid relationships for $5^{\circ}$ bands of latitude around Antarctica. The listed latitude represents that latitude and $4^{\circ}$ south (i.e. $-65=65$ to $69^{\circ} \mathrm{S}$ ) except for -70 which extends south to Antarctica. Months are numbered 1 (Jan) to 12 (Dec) but are ordered according to Southern Hemisphere spring, summer, autumn and winter. Log slopes $\leq-1.6$ are included within the boxed region. Underlined numbers are based on 5 or less values

\begin{tabular}{|c|c|c|c|c|c|c|c|c|c|}
\hline \multirow[t]{2}{*}{ Month } & \multicolumn{9}{|c|}{ Latitude } \\
\hline & -70 & -65 & -60 & -55 & -50 & -45 & -40 & -35 & -30 \\
\hline 10 & - & -1.6 & -1.6 & -1.6 & -1.3 & -1.1 & -1.1 & -0.9 & -1.1 \\
\hline 11 & - & -1.4 & -1.4 & -1.6 & -1.4 & -1.0 & -0.9 & -0.9 & -1.1 \\
\hline 12 & - & -1.9 & -1.8 & -1.7 & -1.4 & -1.2 & -1.0 & -0.8 & -0.6 \\
\hline 1 & -1.4 & -1.5 & -1.7 & -1.7 & -1.1 & -0.8 & -0.7 & -0.7 & -1.0 \\
\hline 2 & -1.5 & -1.5 & -1.7 & -1.8 & -1.6 & -1.2 & -0.9 & -0.9 & -1.0 \\
\hline 3 & -1.4 & -1.6 & -1.7 & -1.7 & -1.8 & -0.9 & -0.8 & -1.0 & -1.0 \\
\hline 4 & - & -1.9 & -1.8 & -1.7 & -1.4 & -0.9 & -1.0 & -0.9 & -0.9 \\
\hline 5 & - & - & -1.8 & -1.8 & -1.5 & -1.2 & -1.1 & -1.0 & -1.1 \\
\hline 6 & - & -2.0 & -1.8 & -1.8 & -1.3 & -1.2 & -1.0 & -1.2 & -1.0 \\
\hline 7 & - & - & -1.9 & -1.8 & -1.5 & -1.1 & -0.9 & -1.0 & -0.7 \\
\hline 8 & - & - & -2.0 & -1.8 & -1.6 & -1.4 & -0.9 & -1.0 & -1.1 \\
\hline 9 & - & - & -1.8 & -1.7 & -1.6 & -1.0 & -1.0 & -0.8 & -0.9 \\
\hline
\end{tabular}



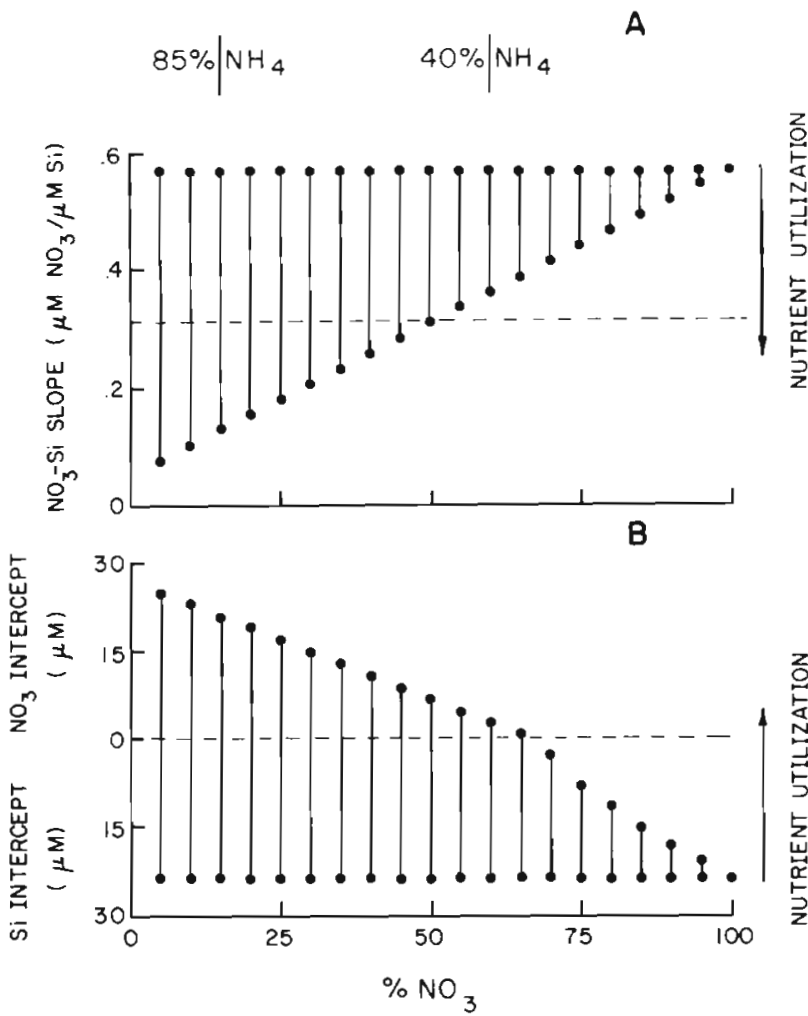

Fig. 7. Results of a simple computer model incorporating the logic used to generate Fig. $12\left(85 \% \mathrm{NH}_{4}\right.$ or $\left.40 \% \mathrm{NH}_{4}\right)$ in Kamykowski \& Zentara (1985). Vertical lines represent ranges of (A) slopes and (B) intercepts of the $\mathrm{NO}_{3}$-Si relationships for different contributions of nitrate as the nitrogen source as the nutrients are utilized. Dashed lines mark position (A) of the log slope criterion $(-0.5)$ used in Figs. 4 and 5 or (B) of the origin

$78 \mu \mathrm{M}$, Si : $\mathrm{N}$ uptake rate $=2.5$ and biogenic silica dissolution rate $=30 \%$ to verify model behavior. Starting from the right in Fig. 7, the single filled-circles mark the slope (Fig. $7 \mathrm{~A}$ ) and projected intercept (Fig. $7 \mathrm{~B}$ ) that occur in the upper ocean under the specified conditions when nitrate is the sole nitrogen source for a predominantly diatom phytoplankton population. Continuing to the left, the pattern of slopes and projected intercepts are represented if $4 \mu \mathrm{M} \mathrm{NO} \mathrm{N}_{3}$ initially serves as the nitrogen source (this condition yields the time course changes in slope and intercept) and if nitrate and ammonium subsequently serve as joint nitrogen sources as given on the $\mathrm{x}$-axis until nitrate and/or silicic acid are depleted. The slope and projected intercept symbols on the same level with the $100 \% \mathrm{NO}_{3}$ position are the initial condition in each case. The vertical lines connect the initial condition to the final condition and thus represent the range of slope and projected intercept changes that occur under each nitrogen source ratio over the course of nutrient utilization. The characteristics of 2 cases $\left(40 \% \mathrm{NH}_{4}\right.$ or $\left.85 \% \mathrm{NH}_{4}\right)$ discussed in $\mathrm{KZ}(1985)$ are accurately repro- duced by the model and are placed in a broader consideration of ammonium as a nitrogen source in Fig. 7 Note that a log slope of -0.5 (slope $=0.3162)$ under the prescribed conditions coincides with the final condition at $50 \% \mathrm{NO}_{3}$ where the projected intercept is $6.9 \mu \mathrm{M}$ $\mathrm{NO}_{3}$, a value that is reasonably close to the origin considering the inherent variability in the NODC data. These properties were responsible for the choice of -0.5 as the log slope criterion in KZ (1985).

Fig. 7 serves as a link between the emphasis of ammonium preference in KZ (1985) and some of the extensions that are required by recent observations. The simple computer model used to generate Fig. 7 is now applied to a range of $\mathrm{Si}: \mathrm{N}$ uptake ratios based on the work of Nelson \& Smith (1986). The same initial conditions are used as in Fig. 7 except that the starting uptake of $4 \mu \mathrm{M} \mathrm{NO}{ }_{3}$ is eliminated and the $\mathrm{Si}: \mathrm{N}$ uptake ratios are 1.0 (commonly measured in temperate zone diatoms; Darley 1977), 2.0, 2.5, 3.0 (2 to 3 is reported for Antarctic diatoms; Jennings et al. 1984, Sakshaug \& Holm-Hansen 1984), or 4.0 (based on the ice edge diatom Si:C molar ratio of 0.6 (Nelson \& Smith 1986) and the assumed Redfield $C: N$ ratio of 6.6 ). Since a $\mathrm{Si}$ : $\mathrm{N}$ uptake ratio of 2 to 3 is commonly reported for Antarctic diatoms, the $\mathrm{Si}$ : $\mathrm{N}$ uptake ratio of 1 may also represent a significant non-diatom representation in the Antarctic phytoplankton community. Fig. 8 demonstrates how the relative contributions of nitrate and ammonium as the nitrogen source interact with the $\mathrm{Si}$ : N uptake ratio to influence the slope (Fig. $8 \mathrm{~A}$ ) and the projected intercept (Fig. $8 \mathrm{~B}$ ) of the resulting $\mathrm{NO}_{3}$ Si relationships. Fig. 8 can be interpreted as phosphate by dividing the slope or the projected intercept (y-axes) and multiplying the $\mathrm{Si}: \mathrm{N}$ ratio by an appropriate $\mathrm{N}: \mathrm{P}$ ratio (e.g. N P $=15$ after Broecker \& Peng 1982). Both the slopes and the projected intercepts are more sensitive to the $\mathrm{Si} \cdot \mathrm{N}$ uptake ratio when nitrate is the dominant nitrogen source. At $\mathrm{Si}: \mathrm{N}$ uptake ratios above 2.5, log slopes below -0.5 overestimate ammonium influence, and at $\mathrm{Si}: \mathrm{N}$ ratios below 2.5, log slopes below -0.5 underestimate ammonium influence. If ice edge diatoms are characterized by Si: N uptake ratios of 4.0 and the range of nitrate contribution of 40 to $65 \%$ discussed by Nelson \& Smith (1986), the predicted slopes are well below the previously selected low log slope criterion of -0.5 without dominant ammonium influence in agreement with Collos \& Slawyk (1986). The projected intercepts predict silicic acid depletion with 10 to $20 \mu \mathrm{M} \mathrm{NO}$ or 0.6 to $1.3 \mu \mathrm{M} \mathrm{PO}_{4}(\mathrm{~N} . \mathrm{P}=15)$ remaining in the water column if low half-saturation constants are assumend (but see Jacques (1983) for silicic acid half-saturation constants of 12 to $22 \mu \mathrm{M}$ for some Antarctic diatoms.

Based on the stated conditions, Fig. 8 suggests that Fig. 7 and the discussion using its criteria (Figs. 4, 5 and 

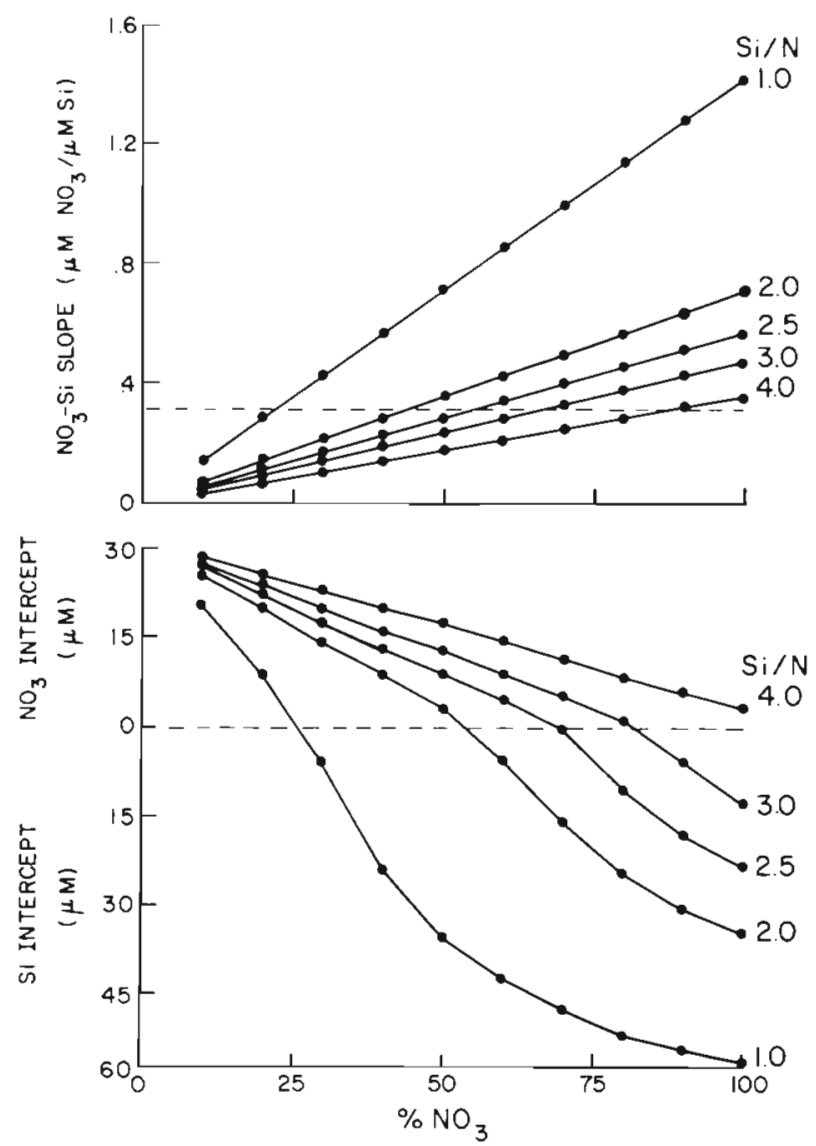

Fig. 8. Results of a simple computer model comparing the interaction of different $\mathrm{Si}: \mathrm{N}$ uptake ratios with different nitrate contributions as the nitrogen source on (A) slopes and (B) intercepts of the $\mathrm{NO}_{3}$-Si relations. Dashed lines mark position $(A)$ of the log slope criterion $(-0.5)$ used in Figs. 4 and 5 or $(B)$ of the origin

6) represent an intermediate condition that can lead to significant misinterpretations of ammonium influence under extreme conditions of the modeled Si : $N$ uptake ratios. The character of Fig. 8, however, depends on the choice of starting nitrate $(31 \mu \mathrm{M})$, starting silicic acid $(78 \mu \mathrm{M})$ and contimuing biogenic silica dissolution rate $(30 \%)$. Since the conditions that led to the field observations discussed by Nelson \& Smith (1986) are not precisely known, model initialization is uncertain, and therefore the modeled patterns may not be accurate. Also, Collos \& Slawyk (1986) suggest that light-limited Antarctic diatoms have C: N ratios $25 \%$ lower than the Redfield ratio. If true for the ice edge diatoms studied by Nelson \& Smith (1986), the Si : N biomass ratio reduces to 3.0 which is closer to the intermediate value of 2.5 used in $\mathrm{KZ}$ (1985). Considering these uncertainties, the patterns in Figs, 4, 5 and 6 may presently be considered to represent differences in regeneration processes with some noise from variation in the $\mathrm{Si}$ : $\mathrm{N}$ uptake ratio.

The relatively sparse process-oriented data from the
Southern Ocean prevent a firm statement on how the character of the nitrogen source and the Si:N ratio interact through the growth season at different locations. Smith (1987) reports that an ice edge spring bloom with a relatively high $\mathrm{Si}: \mathrm{N}$ uptake ratio was observed in the Ross Sea but not in the Weddell Sea. Also, Hewes et al. (1985) have emphasized the role of nannophytoplankton and macrozooplankton grazers that may contribute significantly, if circumstances allow, to Antarctic trophic dynamics (i.e. ammonium flux) later in the growth season. As an example of one scenario, if Antarctic diatoms are characterized by high $\mathrm{Si}$ : $\mathrm{N}$ uptake and biomass ratios, then early growth season primary production by diatoms (Wilson et al. 1986) will initiate a water column plant nutrient pattern toward low log slopes in the $\mathrm{NO}_{3}-\mathrm{Si}$ or $\mathrm{PO}_{4}$-Si relationships (Nelson \& Smith 1986). As the growth season progresses, the addition of non-diatoms to the phytoplankton community (Hewes et al. 1985) may lower the $\mathrm{Si}$ : N uptake and biomass ratios but increasing dependence on ammonium from microbial food web organisms $(<200 \mu \mathrm{m})$ may maintain the tendency toward low log slopes in the $\mathrm{NO}_{3}$-Si or $\mathrm{PO}_{4}$-Si relationships (Holm-Hansen 1985). Other scenarios are not only possible but are likely since relatively high log slopes also occur in the Southern Ocean.

Recently, Martin \& Fitzwater (1968) and Martin \& Gordon (1988) have suggested that the excess major plant nutrients $\left(\mathrm{NO}_{3}, \mathrm{PO}_{4}\right.$ and $\mathrm{Si}$ ) occurring in the Southern Ocean result from iron deficiency. If substantiated, this iron deficiency influences the interpretation of how ammonium and nitrate are partitioned as nitrogen sources. Preferential ammonium uptake that can shut down nitrate utilization above about $2 \mu \mathrm{M} \mathrm{NH}_{4}$ (McCarthy 1981) combined with a differential ammonium availability due to a grazing gradient (Sakshaug \& HolmHansen 1984) was invoked to explain the $\mathrm{NO}_{3}$-Si patterns discussed in KZ (1985). Since iron is required for the synthesis of several photosynthetic electron transport proteins and for the reduction of $\mathrm{CO}_{2}, \mathrm{SO}_{4}$ and $\mathrm{NO}_{3}$ during photosynthetic production of organic compounds, iron deficiency could limit $\mathrm{NO}_{3}$ utilization at ammonium concentrations below $2 \mu \mathrm{M}$. Rueter \& Ades (1987) showed that iron-limited cultures of a freshwater green alga exhibited decreased nitrate uptake but relatively constant ammonium uptake in low light and increased carbon fixation (2.5 times faster) when ammonium rather than nitrate was the nitrogen source. In terms of the 3 circumpolar zones previously discussed (Fig. 6), the most southern zone may be characterized by a nitrate dominance supported by low grazing rates due to the short growth season and adequate iron concentrations contributed by the Antarctic continent (Martin \& Fitzwater 1988). The middle zone may be characterized by an ammonium dominance supported by higher graz- 
ing rates associated with a better developed zooplankton community and reduced iron concentrations, at least during extended stratification, as a result of isolation from land sources and low iron solubilization rates (Holm-Hansen 1985). Deep convection, however, may oppose iron limitation when mixing is frequent. The northern zone is characterized by increasing nitrate and phosphate at the bottom of the euphotic zone and thus the vertical light gradient may be the dominant factor in the relationship between these nutrients and silicic acid in the water column. The long term effect on phytoplankton growth in the 3 zones probably depends on the severity of the proposed iron deficiency and may increase with the age of the growth season.

Finally, the various chemical and biological processes invoked in this discussion must eventually be placed in a physical context. For example, Holm-Hansen (1985) reported that surface seawater from anywhere south of the Polar Front that is incubated on deck exhibits high chlorophyll (25 to $50 \mu \mathrm{g} \mathrm{l}^{-1}$ ) and depleted nitrate at the end of 2 to $3 \mathrm{wk}$. Unless iron is supplied from another source, this observation suggests that elimination of vertical mixing may provide a major stimulus for enhanced biomass production leading to plant nutrient depletion.

The maps, histograms and tables considered here provide a spatial and temporal view of how the log slopes of the $\mathrm{NO}_{3}$-Si and $\mathrm{PO}_{3}$-Si relationships vary in the Southern Ocean. The patterns clearly are related to water masses and seasons but exhibit geographic variability that corresponds with the current view of physical and biological patchiness in the Southern Ocean (Siegfried et al. 1985). This patchiness is especially evident at the frontal regions where mesoscale eddies are prevalent (Nowlin \& Klinck 1988). The present analysis and the discussion demonstrate the complex processes that potentially contribute to the plant nutrient signatures in the water column at a given time and place in the Southern Ocean. Because plant nutrients rarely deplete in the Southern Ocean, their relations can provide an integrated record of the phytoplankton dynamics occurring in a water column from the beginning of the growth season to the time that samples are collected (Jennings et al. 1984). As more data become available to determine the relative contributions of the different processes, the interpretations of the nutrient profiles can be refined and may prove a valuable tool to infer the time course of plankton dynamics in an environment that offers significant sampling problems in time and space.

Acknowledgements. This material is based on research performed with funds provided by NSF Grant OCE 8515496. The staff of NODC and the Triangle Universities Computing Center contributed to the study. Some of the ideas presented benefited from discussions with Drs J. Bishop, B. Frost, D. Nelson and W Smith.

\section{LITERATURE CITED}

Altabet, M. A. (1988). Variations in nitrogen isotopic composition between sinking and suspended particles: implications for nitrogen cycling and particle transformation in the open ocean. Deep Sea Res. 35: 535-554

Broecker, W. S., Peng, T.-H. (1982). Tracers in the Sea. Eldigio Press, Palisades, N.Y.

Checkley, D. M., Entzeroth, L. C. (1985). Elemental and isotopic fractionation of $\mathrm{C}$ and $\mathrm{N}$ by marine planktonic copepods and implications to the marine nitrogen cycle. $\mathrm{J}$ Plankton Res. 7: 553-568

Collos, Y., Slawyk, G. (1986). ${ }^{13} \mathrm{C}$ and ${ }^{15} \mathrm{~N}$ uptake by marine phytoplankton-IV. Uptake ratios and the contribution of nitrate to the productivity of Antarctic waters (Indian Ocean sector). Deep Sea Res. 33: 1039-1051

Darley, W. M. (1977). Biochemical composition. In: Werner, D (ed.) The biology of diatoms. Univ. of California Press, Berkeley, p. 198-223

Glibert, P. M., Biggs, D. C., McCarthy, J. J. (1982). Utilization of ammonium and nitrate during austral summer in the Scotia Sea. Deep Sea Res. 29: 837-850

Gordon, K. L., Molinelli, E. J., Baker, T N. (1982). Southern Ocean Atlas. Columbia Univ. Press, New York

Harris, G. P. (1986). Phytoplankton ecology: structure function and ecology. Chapman and Hall, London

Hewes, C. D., Holm-Hansen, O., Sakshaug, E. (1985). Alternate carbon pathways at lower trophic levels in the Antarctic food web. In: Siegfried, W. R., Condy, P. R., Laws, R. M. (eds.) Antarctic nutrient cycles and food webs. SpringerVerlag, Berlin, p. 277-283

Holm-Hansen, O. (1985). Nutrient cycles in Antarctic marine ecosystems. In: Siegfried, W R., Condy, P. R., Laws, R. M. (eds.) Antarctic nutrient cycles and food webs. SpringerVerlag, Berlin, p. 6-10

Ikeda, Y., Siedler, G., Zwierz, M. (1989). On the variability of Southern Ocean front locations between Southern Brazil and the Antarctic Peninsula. J. geophys. Res. 94: $4757-4762$

ISSCO (1981). DISSPLA user's manual: Version 9.10. Integrated Software Systems Corporation, San Diega, California

Jacques, G. (1983). Some ecophysiological aspects of the antarctic phytoplankton. Polar Biol. 2: 27-33

Jennings, Jr, J. C., Gordon, L. I., Nelson, D. M. (1984). Nu trient depletion indicates high primary productivity in the Weddell Sea. Nature Lond. 309: 51-54

Kamykowski, D., Zentara, S.-J. (1985). Nitrate and silicic acid in the world ocean: patterns and processes. Mar. Ecol. Prog. Ser. 26: 47-59

Kamykowski, D., Zentara, S. J. (1986). Predicting plant nutrient concentrations from temperature and sigma-t in the upper kilometer of the world ocean. Deep Sea Res. 33: 89-105

LeJehan, S. Treguer, P. (1983). Uptake and regeneration $\triangle$ Si/ $\triangle N / \triangle P$ ratios in the Indian sector of the Southern Ocean. Polar Biol. 2:127-136

LeJehan, S., Treguer, P. (1985). The distribution of inorganic nitrogen, phosphorus, silicon and dissolved organic matter in surface and deep waters of the Southern Ocean. In: Siegfried, W R., Condy, P. R., Laws, R. M. (eds.) Antarctic nutrient cycles and food webs. Springer-Verlag. Berlin, $\mathrm{p}$. 22-29

Martin, J. H., Fitzwater, S. E. (1988). Iron deficiency limits phytoplankton growth in the north-east Pacific subarctic. Nature Lond. 331: 341-343

Martin, J. H., Gordon, R. M. (1988). Northeast Pacific iron 
distributions in relation to phytoplankton productivity. Deep Sea Res. 35: 177-196

McCarthy, J. J. (1981). The kinetics of nutrient utilization Can. Bull. Fish. Aquat. Sci. 210: 211-233

Nelson, D. M., Gordon, L. I. (1982). Production and pelagic dissolution of biogenic silica in the Southern Ocean. Geochem. Cosmochim. Acta 46: 491-501

Nelson, D. M., Smith, W. O., Jr (1986). Phytoplankton bloom dynamics of the western Ross Sea ice edge - II Mesoscale cycling of nitrogen and silicon. Deep Sea Res. 33 $1389-1412$

Nowlin, Jr., W. D., Klinck, J. M. (1986). The physics of the Antarctic circumpolar Current. Rev. Geophys. Space Phys. 24: $469-491$

Olson, R. J. (1980). Nitrate and ammonium uptake in Antarctic waters. Limnol. Oceanogr 25: 1064-1074

Olson, R. J. (1981). Differential photoinhibition of marine denitrifying bacteria: a possible mechanism for the formation of the primary nitrite maximum. J. Plankton Res. 39 $227-238$

Omori, M., Ikeda, T. (1984). Methods in marine zooplankton ecology, John Wiley \& Sons, New York

Redfield, A. C., Ketchum, B. H., Richards, F. A. (1963). The influence of organisms on the composition of seawater. In Hill, M. N. (ed.) The sea, Vol. 2. Interscience. New York, p $26-77$

Rueter, J. C., Ades, D. R. (1987). The role of iron nutrition in photosynthesis and nitrogen assimilation in Scenedesmus quadricauda (Chlorophyceae). J. Phycol. 23: 452-457

Sakshaug, E., Holm-Hansen, O. (1984). Factors governing pelagic production in polar oceans. In: Holm-Hansen, $O$. Bolis, L., Gilles, R. (eds.) Marine phytoplankton and productivity. Springer-Verlag, Berlin, p. 1-18

This article was submitted to the editor
SAS Institute Inc. (1985). SAS user's guide: Basics: Version 5 edn SAS, Cary, North Carolina

Siegfried, W. R. Condy, P. R., Laws, R. M. (1985). Antarctica nutrient cycles and food webs. Springer-Verlag. Berlin

Smith, S. V., Kimmerer, W J., Walsh, T. W. (1986). Vertical flux and biogeochemical turnover regulate nutrient limitation of net organic production in the North Pacific Gyre Limnol. Oceanog. 31. 161-166

Smith, W. O., Jr (1987). Phytoplankton dynamics in marginal ice zones. Oceanogr mar Biol. A. Rev. 25: 11-38

Sverdrup, H. U., Johnson, M. W. Fleming, R. H. (1942). The oceans: their physics, chemistry and general biology. Prentice-Hall, Inc., Englewood Cliffs, N. J.

Takahashi, T., Broecker, W. S., Langer, S. (1985). Redfield ratio based on chemical data from isopycnal surfaces. J. geophys. Res. 90: 6907-6924

Tchernia, P. (1980). Descriptive regional oceanography. Pergamon Press, Oxford

Wada, E. (1980). Nitrogen isotope fractionation and its significance in biogeochemical processes occurring in marine environments. In: Goldberg, E. D. (ed.) Isotope marine chemistry. Uchida Rokakuho pub. Co. Ltd, Tokyo, p. 375-398

Wilson, D. L.,Smith, Jr, W. O., Nelson, D. M. (1986). Phytoplankton bloom dynamics of the western Ross Sea ice edge - I Primary productivity and species specific production. Deep Sea Res. 33: 1357-1387

Zentara, S.-J., Kamykowski, D. (1977). Latitudinal relationships among temperature and selected plant nutrients along the west coast of North and South America. J. mar Res. 35: 321-337

Zentara, S.-J., Kamykowski, D. (1981). Geographic variations in the relationship between silicic acid and nitrate in the South Pacific Ocean. Deep Sea Res. 28: 455-465

Manuscript first received: February 8, 1989

Revised version accepted: August 9, 1989 